\title{
Computer simulations on oxidative stress-induced reactions in SARS-CoV-2 spike glycoprotein: a multi-scale approach
}

\author{
Oscar Bertran ${ }^{1}$ (D) $\cdot$ Didac Martí $^{2} \cdot$ Juan Torras $^{2}$ (D) $\cdot$ Pau Turon $^{3}$ (D) $\cdot$ Carlos Alemán $^{2,4}$ (D)
}

Received: 8 September 2021 / Accepted: 21 December 2021 / Published online: 18 February 2022

(c) The Author(s) 2022

\begin{abstract}
Oxidative stress, which occurs when an organism is exposed to an adverse stimulus that results in a misbalance of antioxidant and pro-oxidants species, is the common denominator of diseases considered as a risk factor for SARS-CoV-2 lethality. Indeed, reactive oxygen species caused by oxidative stress have been related to many virus pathogenicity. In this work, simulations have been performed on the receptor binding domain of SARS-CoV-2 spike glycoprotein to study what residues are more susceptible to be attacked by $\cdot \mathrm{OH}$, which is one of the most reactive radicals associated to oxidative stress. The results indicate that isoleucine (ILE) probably plays a crucial role in modification processes driven by radicals. Accordingly, QM/MM-MD simulations have been conducted to study both the -OH-mediated hydrogen abstraction of ILE residues and the induced modification of the resulting ILE radical through hydroxylation or nitrosylation reactions. All in all, in silico studies show the importance of the chemical environment triggered by oxidative stress on the modifications of the virus, which is expected to help for foreseeing the identification or development of antioxidants as therapeutic drugs.
\end{abstract}

\section{Graphic abstract}

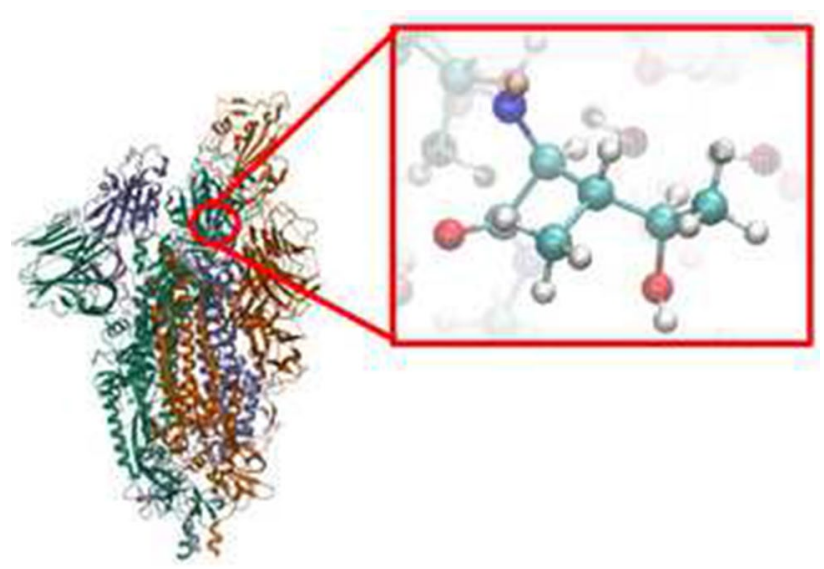

Keywords Hydrogen abstraction · Isoleucine $\cdot$ Molecular dynamics $\cdot$ Reactive oxygen species $\cdot$ Receptor binding domain . Spike protein

\section{Introduction}

Oxidative stress occurs when an organism is exposed to an adverse stimulus that results in a misbalance of antioxidant and pro-oxidant species [1]. Accumulated research

Extended author information available on the last page of the article demonstrates that oxidative stress is a relevant factor associated with infectious diseases, such as Hepatitis B and C, Herpes Simplex, Human Immunodeficiency and Influenza viruses [2-4]. Furthermore, the spike protein of SARS$\mathrm{CoV}-2$ has been found to noticeably increase the levels of reactive oxygen species (ROS) [5, 6]. Oxidative stress is a common denominator of diseases considered as a risk factor 
for SARS-CoV-2 lethality (i.e., cancer, hypertension, vascular diseases and diabetes) [7, 8]. Some authors have related ROS with virus pathogenicity [9-11] considering the release of ROS and pro-oxidant cytokines as a result of virus activation of phagocytic cells, interfering in the balance between antioxidants and pro-oxidants of host cells [12]. Indeed, recent studies have evidenced relationships between oxidative stress and SARS CoV-2 infection, suggesting that ROS could be critical for disease progression [13-16].

Among ROS, hydroxyl radical $(\cdot \mathrm{OH})$ deserves special attention since it is one of the most reactive radicals, exhibiting a very short half-life $\left(\sim 1 \mathrm{~ns}\right.$ at $\left.37{ }^{\circ} \mathrm{C}\right)$ and extremely high reaction rate constants [17]. ROS are able to modify molecules in their close environment and lead to diseases related to cell injury when a misbalance occurs (e.g., pneumonia, nervous system diseases and leukemia) [18-21].

We focus the present work on the direct interaction between the $\cdot \mathrm{OH}$ specie and the homo-trimeric spike protein of SARS-CoV-2 in order to elucidate how the glycoprotein will be affected by the radical. The knowledge of such interaction could provide additional understanding about the virus behavior in physiological environments that might result in functional changes. Furthermore, it aims to contribute to the development of antioxidants as therapeutic drugs to minimize such risk.

We focus on the present work on the interaction between the $\cdot \mathrm{OH}$ species and the homo-trimeric spike protein of SARS-CoV-2 in order to elucidate how the glycoprotein will be affected by the radical. The knowledge of such interaction is expected to allow for a better understanding about the virus behavior in physiological environments that might result in functional changes. Furthermore, it aims to contribute to the development of antioxidants as therapeutic drugs to minimize such risk.

\section{Methods}

\section{Construction of the spike molecular model}

The cryoelectron microscopy structure of the homo-trimeric spike glycoprotein of SARS-CoV-2 (PDBid: 6vxx), which solved at a resolution of $2.80 \AA$ [22], was taken from the Protein Data Bank and used to prepare the initial model. The missing residues (i.e., 44-55, 88, 89, 118-139, 147-159, 217-236, 417-429, 445-462, 476, 595-614, 651-653, 802-828, 1162-1175, 1236-1258, 1268-1280, 1292-1294, 1307- 1309, 1338-1357, 1550-1556, 1562-1585,
1610-1616, 1716-1735, 1772-1783, 1923-1948, 2283-2296, 2360-2380, 2389-2401, 2459-2479, 2661-2263, 2671-2677, 2687-2706, 2837-2856, 2893-2905 and 3044-3071) were incorporated using the Modeler algorithm [23] implemented in the UCSF Chimera program [24] and the Z-DOPE (Discrete Optimized Protein Energy), statistical potential based for the choice of best model (i.e., that with the lowest Z-DOPE) for each conformational state, among the generated ones.

The homo-trimeric protein model with $9 \mathrm{Na}^{+}$to neutralize the charge was then submerged in a previously equilibrated water box of $19 \times 20 \times 22 \mathrm{~nm}^{3}$. Any water molecule that overlapped with any of the atoms belonging to the protein spike model was removed. After that, 440 randomly selected water molecules were replaced by $440 \cdot \mathrm{OH}$ radicals. With the incorporation of an excessive amount of radicals, it was sought to increase the probability of contact within a limited time trajectory. Finally, the system contained a total of 212,198 water molecules. The model was completed by inserting randomly $440 \mathrm{Na}^{+}$and $440 \mathrm{Cl}^{-}$ions until reaching a concentration to reproduce physiological conditions. Then, the model was processed with the LEaP program [25] to add hydrogen atoms to the protein and to generate Amber topology files and coordinates files. Accordingly, the model presented 691,739 explicit atoms.

\section{Force field}

All simulations were performed using the Amber 18 simulation suite [26]. Protein atoms were modeled using the Amber ff14SB force field [27], the glycan atoms included in the cryo-EM coordinates were modeled using the Glycam06 force field [28], and water atoms were modeled using the TIP3P force field [29]. This combination of force field parameters was found to be appropriate for the MD modeling of the spike glycoprotein of SARS-CoV-2 [30]. The geometrical and nonbonding parameters for the hydroxyl radical $(\cdot \mathrm{OH})$ were taken from Roeselová et al. [31]. In brief, geometrical parameters were taken from geometry optimizations at the MP2/aug-cc-pVTZ, while electrostatic atomic charges $(-0.4$ and +0.4 for oxygen and hydrogen atoms, respectively) were obtained at the MP2/6-31G level. The van der Waals parameters (i.e., the atomic radius, R, and the hardness, $\varepsilon$ ) for the oxygen atom were $\mathrm{R}=1.798 \AA$ and $\varepsilon=0.156 \mathrm{kcal} / \mathrm{mol}$, while they were set to zero for the hydrogen atom. Finally, the $\cdot \mathrm{O}-\mathrm{H}$ stretching force constant was derived from the experimental harmonic frequency, $3738 \mathrm{~cm}^{-1}$ [32], as $k_{s}=1115.4 \mathrm{kcal} /\left(\mathrm{mol} \cdot \AA^{2}\right)$. 


\section{Computational details for classical MD simulations}

Equilibration calculations were started by relaxing the protein regions filled with the UCSF Chimera program [24], which was achieved by applying the limited-memory Broyden-Fletcher-Goldfarb-Shanno quasi-Newton algorithm methodology to the added residues meanwhile the rest of the system was kept frozen. Next, the whole system was submitted to 2500 steps of full conjugate gradient minimization to relax conformational and structural tensions.

The Langevin dynamics method [33] was used to heat the system and to rapidly equilibrate its pressure and temperature. The relaxation times used for the coupling were $10 \mathrm{ps}$ for both temperature and pressure. The temperature was increased from 0 to $500 \mathrm{~K}$ using 20 ps simulation in the NVT ensemble, keeping the frozen the atoms of the spike, maintaining the pressure at 1.034 bar and using an integration time step of $2 \mathrm{fs}$. After this, the temperature was decreased to $310 \mathrm{~K}$ using $0.2 \mathrm{~ns}$ of NVT MD simulation at $1.034 \mathrm{bar}$. In the latter process, the spike protein was still frozen. Then, $2 \mathrm{~ns}$ in the NPT ensemble was conducted at $310 \mathrm{~K}$ to relax the whole system, including the protein, and the density (integration step: $2 \mathrm{fs}$; pressure: 1.034 bar). The last snapshot of this relaxation was used as starting point of the $250 \mathrm{~ns}$ NPT production trajectory at $310 \mathrm{~K}$ (integration step: $2 \mathrm{fs}$; pressure: 1.034 bar). Snapshots were stored every $10 \mathrm{ps}$.

Nonbonding pairs list was updated every 12 steps. Periodic boundary conditions were applied using the nearest image convention and the atom pair cutoff distance used to compute the van der Waals interactions was set at $10.0 \AA$. Beyond the cutoff distance, electrostatic interactions were calculated by using particle mesh of Ewald [34].

\section{Computational details for hybrid QM/MM-MD simulations}

Hybrid quantum mechanics/molecular mechanics (QM/ MM)-MD simulations were performed considering a subsystem containing the receptor binding domain (RBD) of SARS-CoV-2 in physiological conditions. In hybrid QM/ MM-MD simulations the atomic motions are handled by $\mathrm{MD}$, while energies and forces are calculated by dividing the system into two different parts. The reacting radical $(\cdot \mathrm{OH}$ or $\cdot \mathrm{NO})$ and ILE472 residue are treated at the quantum mechanical (QM) level while molecular mechanics (MM) are applied to the rest of the system (all the residues included in the RBD of SARS-CoV-2 with the exception of ILE472 residue and all the ions and water molecules) by using the classical potential energy function included in Amber program [26] and the set of force field parameters described above for classical MD simulation.

A total of 40 QM/MM-MD trajectories were conducted to study the $\cdot \mathrm{H}$ abstraction from the ILE472 residue. Previously to the production of the QM/MM-MD trajectories, selected snapshots taken from the classical MD simulation were modified by approaching the selected $\cdot \mathrm{OH}$ radical, which was at a distance $<4 \AA$ from the reacting ILE, to a distance $R$ (with $R=1.4$ or $1.7 \AA$ ) of the ILE472 hydrogen atom chosen as reaction site. A total of 10 and $30 \mathrm{QM} / \mathrm{MM}-\mathrm{MD}$ trajectories were conducted for $R=1.4$ or $1.7 \AA$, respectively. After minimization at the MM level, these modified systems were heated up to $310 \mathrm{~K}$ and, finally, equilibrated by classical MD using a NPT ensemble for $1 \mathrm{~ns}$ ( 2 fs time steps). In both thermalization and equilibrations steps the distance $R$ between the oxygen atom of the $\cdot \mathrm{OH}$ radical and the ILE472 reacting site was restrained by a force constant of $10 \mathrm{kcal} /$ $\mathrm{mol} \cdot \AA^{2}$, whereas the rest of conditions were identical to those described above.

On the other hand, QM/MM-MD trajectories for the hydroxylation and nitrosylation of the -ILE472 (the radical ILE residue obtained by $\cdot \mathrm{H}$ abstraction) were performed using a similar procedure. In this case $\cdot \mathrm{OH}$ and $\mathrm{NO}$ radicals were placed at distance $R=1.6$ or $2.0 \AA$ from the $\cdot$ ILE472 reaction site. A total of $8 \mathrm{QM} / \mathrm{MM}-\mathrm{MD}$ runs (4 for hydroxylation and 4 for nitrosylation), which were 0.2 ps long each, were conducted.

Hybrid QM/MM-MD simulations were run using PUPIL interface [35, 36], which allows to link, among others, QM calculations from NWChem [37] program with MD simulations from Amber $[18,26]$ program. The starting structures used for the QM/MM-MD simulations through the NWChem-PUPIL-Amber interface were extracted from the last classical MD equilibration snapshot. Subsequently, the reacting ILE residue with the closest neighbor atom of the adjacent residues and the selected $\cdot \mathrm{OH}$ radical was changed to a QM description, while the rest of the system remained within the MM framework. Thus, all atoms in the QM region were described by combining M06-2X functional $[38,39]$, which is a meta-generalized gradient DFT especially developed for thermochemical kinetics studies, with the $6-31+\mathrm{G}(\mathrm{d})$ basis set. After that, the systems were allowed to relax for $0.1 \mathrm{ps}$ ( 0.5 fs time step) restricting the distance $R$ between the oxygen atom of the radical and the ILE472 or -ILE472 reacting site and using a constant pressure simulation with the same parameters previously used 


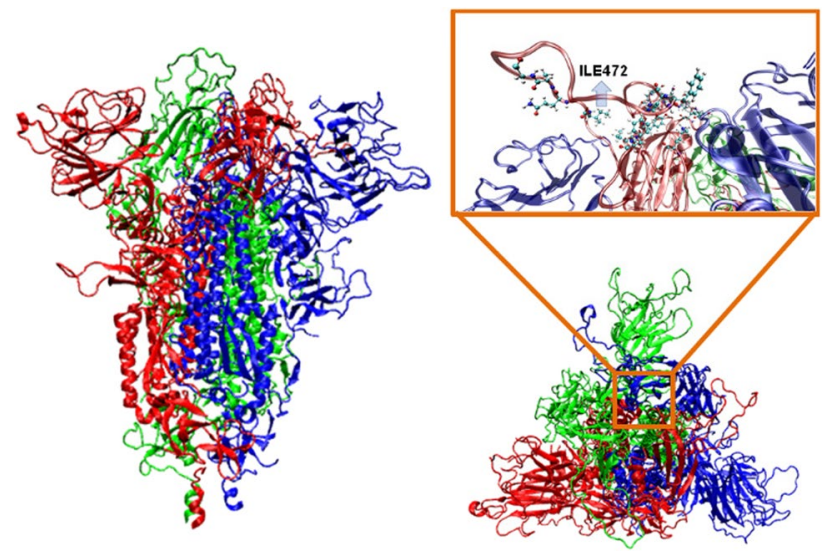

Fig. 1 Lateral and frontal views of the SARS-CoV-2 homo-trimeric spike protein. The subset image (in the box) at the right indicates with balls the residues that are crucial for ACE2 binding

for fully classical MD simulations. Periodic boundary conditions were applied in the preparation of the NWChem input so as to wrap neighboring point charges around the quantum region. The, production QM/MM-MD trajectories ( $0.4 \mathrm{ps}$ for

(a)

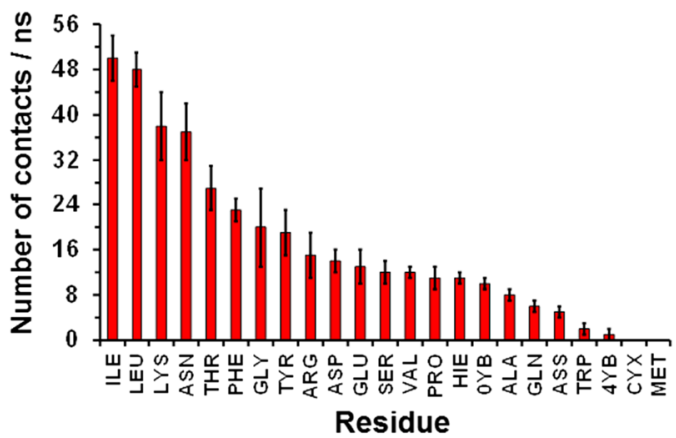

(c)

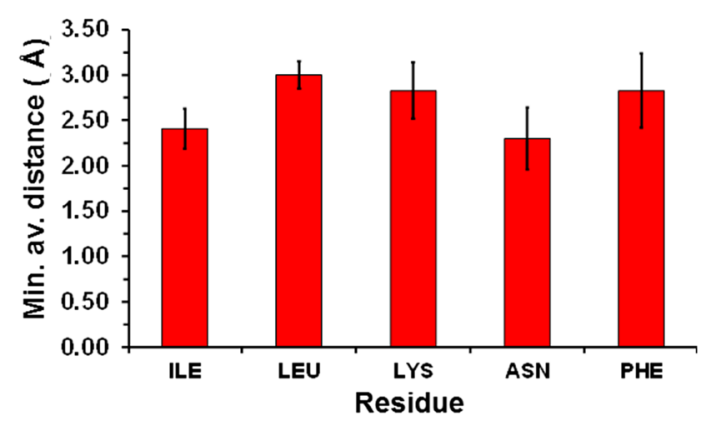

Fig. 2 Results from classical MD simulations involving the SARS$\mathrm{CoV}-2$ homo-trimeric spike protein and the $\cdot \mathrm{OH}$ radical: a Number of contacts between the different residues of the protein and each radical type (cutoff distance $<4 \mathrm{~A}$ ); $\mathbf{b}$ Accumulated contact time between the residues and the protein residues (only residence times longer than $\cdot \mathrm{H}$ abstraction and $0.2 \mathrm{ps}$ for hydroxylation and nitrosylation) were run and the coordinates were saved every $10 \mathrm{fs}$ for subsequent analyses.

\section{Results and discussion}

Initially, tentative classical molecular dynamics (MD) simulations were performed considering the SARS-CoV-2 spike homo-trimeric glycoprotein [22], as shown in Fig. 1. This was introduced in a previously equilibrated box with 212,198 water molecules and $440 \cdot \mathrm{OH}$ radicals explicitly defined. The whole system was described at the molecular mechanics (MM) level using the Amber force field [25]. After a production MM-MD trajectory of $250 \mathrm{~ns}$ at $310 \mathrm{~K}$ using the procedure described in the Methods section, the preferred $\cdot \mathrm{OH} \cdots$ residue close contacts was estimated.

As the life time of the $\cdot \mathrm{OH}$...residue contacts was found to be very short ( $\leq 80 \mathrm{ps}$ ), analyses were performed in blocks of $1 \mathrm{~ns}$ (i.e., the $\cdot \mathrm{OH}$ half-life time) for the last $150 \mathrm{~ns}$ of the trajectory (i.e., once the complete equilibration of the system was ensured), and the values averaged. The highest

(b)

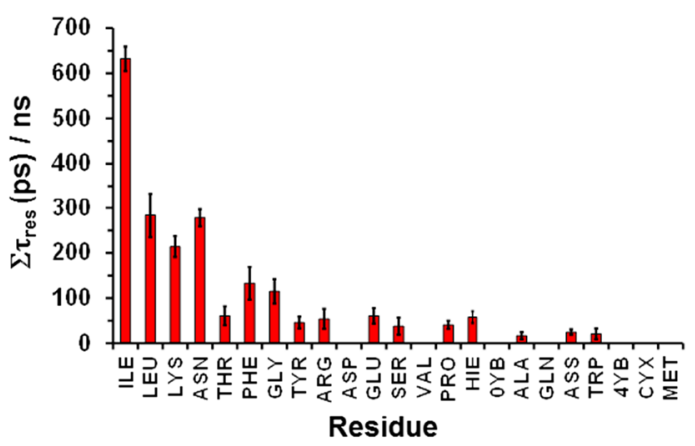

(d)

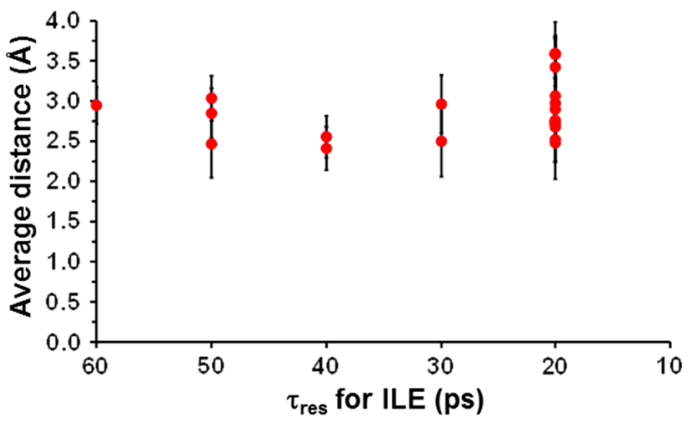

2 ps have been considered); c Minimum averaged contact distance between the five residues with higher accumulated constant time and the $\cdot \mathrm{OH}$ radical; d Averaged contact distance between $\cdot \mathrm{OH}$ radical and the ILE residue as a function of the residence time 
number of close contacts with $\cdot \mathrm{OH}$, which were defined using a threshold distance of $4.0 \AA$, was obtained for the L-Isoleucine (ILE) residue, followed by L-Leucine (LEU) and L-Lysine (LYS) (Fig. 2a). These results are consistent with those of an early study where the reaction of the $\cdot \mathrm{OH}$ with the aliphatic $\mathrm{C}-\mathrm{H}$ bonds of amino acids was studied by ${ }^{2} \mathrm{H}$ NMR [40]. It was found that ${ }^{1} \mathrm{H} /{ }^{2} \mathrm{H}$ exchange by $\cdot \mathrm{H}$ abstraction occurred in the following descending order: LEU $>$ ILE $>$ VAL $>$ ARG $>$ LYS $>$ TYR $>\ldots$. The residence

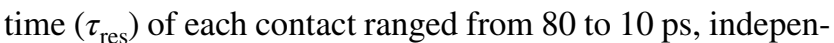
dently of the residue. Representation of the accumulated $\tau_{\text {res }}$ along one ns $\left(\Sigma \tau_{\text {res }}\right)$ for the different residues (considering only $\tau_{\text {res }} \geq 20 \mathrm{ps}$ ) indicated that ILE exhibited the longest contact (Fig. 2b), suggesting that such residue may play a crucial role in modification processes driven by radicals. Interestingly, analysis of the distance between the two closest atoms in the contacts with $\tau_{\text {res }} \geq 20$ ps reveals slightly shorter values for ILE and ASN than for other residues. This is also shown when the average distance for the closest contact is compared, as is depicted for the five residues with the highest $\Sigma \tau_{\text {res }}$ (Fig. 2c). Moreover, analysis of the average distance for contacts between $\cdot \mathrm{OH}$ and ILE residues with $\tau_{\text {res }} \geq 20$ ps revealed values systematically short, independently of $\Sigma \tau_{\text {res }}$ (Fig. 2d).

Chemical reactions related to $\cdot \mathrm{OH}$ attack to the residues of viral proteins are relevant to understand the influence of the oxidative stress on modification and/or degradation processes [41]. Modifications in glycoproteins can cause an increase in viral infectivity in primates and humans [42]. For example, ILE at position 544 augments the infectivity of Ebola virus (EBOV) and Reston virus (RESTV), regardless of host species, which was attributed to a more pronounced viral fusion activity [43]. Among coronavirus modifications, earlier findings suggested that a single-point mutation at the $\mathrm{RBD}$, which is a core region that binds the cellular receptor human angiotensin-converting enzyme 2 (ACE2; see Fig. 1) and mediates the fusion of the viral and cellular membranes, could affect the recognition process [42].

Focusing on ILE, $\cdot \mathrm{OH}$ converts the residue into a radical by $\cdot \mathrm{H}$ abstraction. Early studies performed using ${ }^{2} \mathrm{H}$ NMR spectra on amino acids showed that ILE, LEU and VAL behave similarly [40]. The oxidative modification of such aliphatic amino acids, when are not integrated in the sequence of proteins, depends on their radical stability and, as a consequence, the preferred abstraction occurs at the branch point $\left(\mathrm{C}^{\beta}-\mathrm{H}\right.$ for ILE, $\mathrm{C}^{\gamma}-\mathrm{H}$ for LEU and $\mathrm{C}^{\beta}-\mathrm{H}$ for $\mathrm{VAL}$ ). For such reasons, to investigate how the amino acids inserted in the protein structure are affected by the radical species merits attention because the reaction ability of those radicals can affect the binding region stability.

Considering the tendency of $\cdot \mathrm{OH}$ to be attracted by ILE in the spike of SARS-CoV-2, the radical-mediated deprotonation reaction of such residue was examined by means of a hybrid QM/MM-MD scheme using M06-2X Density functional. This technique has been previously used in large biological systems [44]. For this purpose, ILE residue showing the highest amount of close contacts with $\mathrm{OH}$ in classical MM-MD trajectories was selected for hybrid QM/MM-MD simulations. This corresponds to ILE472, which is located at the RBD [45]. Indeed, the enhanced transmissibility of SARS-CoV-2 UK variant has been related to changes within RBD of the spike [46].

For QM/MM-MD simulations, an $\cdot \mathrm{OH}$ radical close to the ILE472 residue, together with the last and first atom of the adjacent residues (i.e., the carbonyl carbon atom of GLU471 and the peptidic nitrogen atom of TYR473), was treated at the QM level (active zones). The rest of the system, which consisted on the RBD region, 103 ions $\left(53 \mathrm{Cl}^{-}\right.$and $\left.50 \mathrm{Na}^{+}\right)$ and 15,928 water molecules remained described classically. Ten representative snapshots, with one $\mathrm{OH}$ radical close $(<3.5 \AA)$ to each of the ten hydrogen atoms of the ILE residue (i.e., $\mathrm{H}^{\alpha}, \mathrm{H}^{\beta}, \mathrm{H}^{\gamma 11}, \mathrm{H}^{\gamma 12}, \mathrm{H}^{\gamma 21}, \mathrm{H}^{\gamma 22}, \mathrm{H} \gamma^{23}, \mathrm{H}^{\delta 1}, \mathrm{H}^{\delta 2}$ and $\mathrm{H}^{\delta 3}$ in Fig. 3a), were randomly chosen among the last $30 \mathrm{~ns}$ of the classical MD simulation. As $\cdot \mathrm{H}$ abstraction is the first step in the $\cdot \mathrm{OH}$-mediated oxidation of aliphatic amino acids [47], for the active zone of each selective snapshot the oxygen atom of $\cdot \mathrm{OH}$ radical was initially approached $1.4 \AA$ from the corresponding hydrogen atom of ILE472. After equilibration using the protocol described in the ESI, QM/ MM-MD simulations were run for $0.5 \mathrm{ps}$.

After 30-60 fs, $\mathrm{H}$ abstraction was observed for all the hydrogens with exception of $\mathrm{H}^{\beta}$ (Fig. 3b). Analysis of the total energy for the resulting systems (listed in Fig. 3b) revealed that the order of stability of the products from $\cdot \mathrm{OH}$-mediated abstraction is ranked as follows: $\mathrm{H}^{\gamma 1}>\mathrm{H}^{\gamma 2}>\mathrm{H}^{\delta}>\mathrm{H}^{\alpha}$. However, the QM energy of the active zone was practically identical for all systems, suggesting that the stability of the products is mainly defined by the surrounding protein environment. Although earlier experimental studies evidenced that the abstraction of an $\cdot \mathrm{H}$ atom from the Gly residue usually occurs at the $\mathrm{C}-\mathrm{H}^{\alpha}$ bond $[48,49]$, a more recent ab initio study on a LEU dipeptide model (i.e., $\mathrm{NH}_{2} \mathrm{COCHRNHCHO}$ with $\mathrm{R}=\mathrm{CH}_{2} \mathrm{CH}\left(\mathrm{CH}_{3}\right)_{2}$ ) proved the importance of steric interactions in $\cdot \mathrm{H}$ abstraction 
Fig. 3 Schemes displaying a atoms labeling for ILE and $\mathbf{b}$, c Successful $\mathrm{H}$ abstraction processes obtained using MQ/ MM-MD simulations when a (C-) $\mathrm{H} \cdots$. OH distance of b $1.4 \AA$ or c $1.7 \AA$ was initially imposed

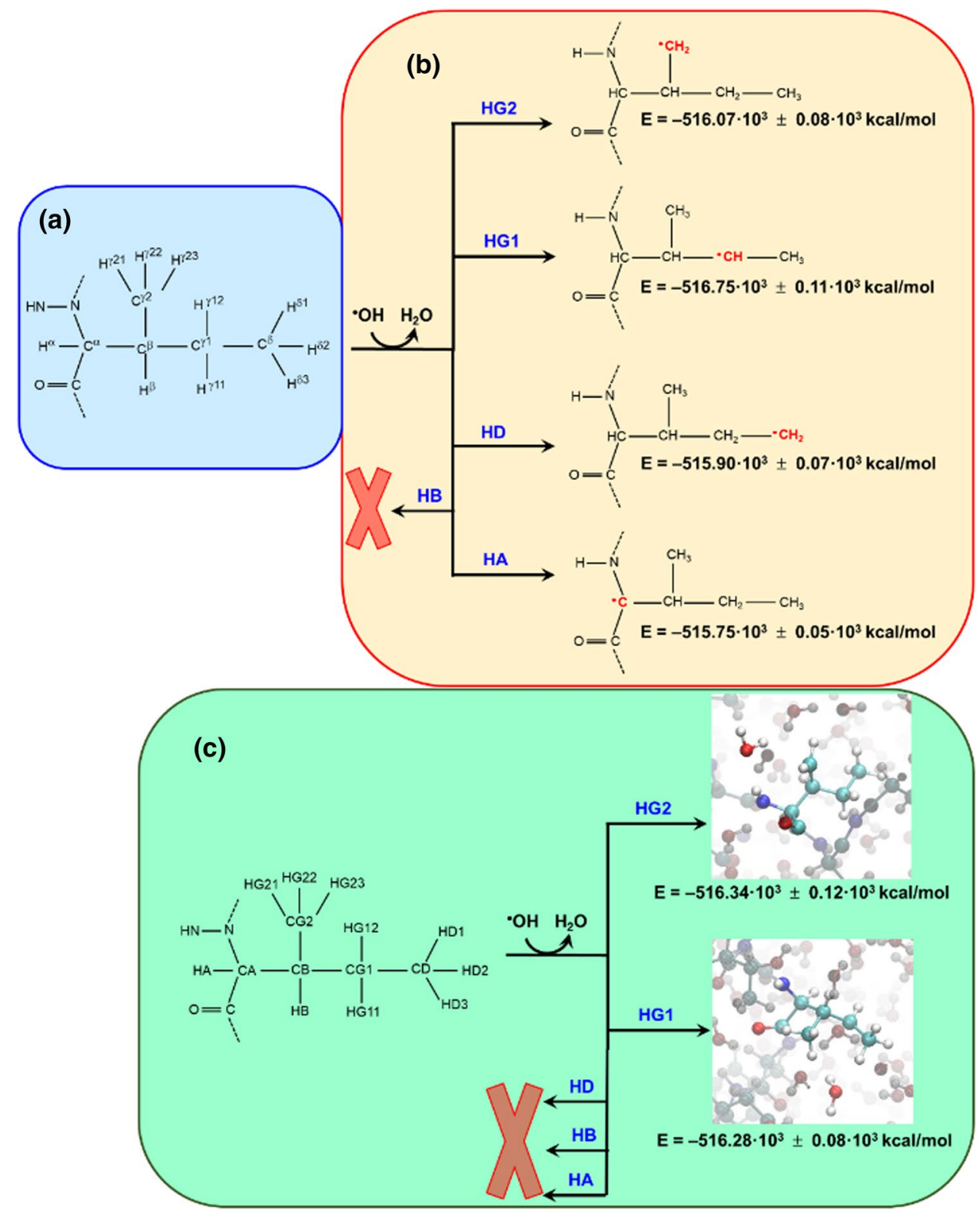

[41]. Authors did not find a clear distinction among $\mathrm{C}^{\beta}-\mathrm{H}$, $\mathrm{C}^{\gamma}-\mathrm{H}$ and $\mathrm{C}^{\delta}-\mathrm{H}$ sites while the reactivity of the $\mathrm{C}^{\alpha}-\mathrm{H}$ bond was lower, which was attributed to steric effects and the tendency of the $\cdot \mathrm{OH}$ to form hydrogen bonds with $\mathrm{NH}$ and $\mathrm{C}=\mathrm{O}$ groups [41]. More recently, $\mathrm{ab}$ initio and DFT calculations on a quite similar dipeptide model but with less hydrogen bonding capacity at the $\mathrm{N}$-terminus (i.e., $\mathrm{CH}_{3} \mathrm{CONHCHRCOOH}$ with $\left.\mathrm{R}=\left(\mathrm{CH}_{2}\right)_{4} \mathrm{CH}_{3}\right)$ revealed favored $\cdot \mathrm{H}$ abstractions for the $\mathrm{C}^{\alpha}-\mathrm{H}$ and $\mathrm{C}^{\varepsilon}-\mathrm{H}$ bonds [50].

In a very recent work, Gross and coworkers [51] used ${ }^{18} \mathrm{O}$ isotopic labeling to study the $\cdot \mathrm{H}$ abstraction from LEU and ILE C-H bonds belonging to short and, probably, non-structured peptides. These authors found that the preferred abstraction occurred at the branch point (i.e., $\mathrm{C}^{\gamma}-\mathrm{H}$ and $\mathrm{C}^{\beta}-\mathrm{H}$ for LEU and ILE, respectively), which was attributed to the classical stability ranking of aliphatic radicals (tertiary $>$ secondary $>$ primary). Instead, the $\cdot \mathrm{OH}$-mediated .H abstraction of ILE, as amino acid, followed by ${ }^{2} \mathrm{H}$ NMR detection of ${ }^{1} \mathrm{H} /{ }^{2} \mathrm{H}$ induced exchange indicated that the $\mathrm{C}^{\gamma^{2}-\mathrm{H}}$ and $\mathrm{C}^{\delta}-\mathrm{H}$ sites are the most reactive [40]. Overall, the results allow us to suggest that the discrepancies among the different studies in the most reactive site come from the flexibility of the alkyl side chain of ILE and the ability of the radical to interact with the surrounding chemical 
environment. Furthermore, it depends on the flexibility or rigidity of the backbone that, in turn, is influenced by the secondary and tertiary structure of the peptide / protein.

Theoretical QM calculations on model dipeptides $[41,50]$ showed that the characteristic distances in the $\mathrm{C} \cdots . . \mathrm{H} \cdots . \mathrm{OH}$ transition state associated with the $\cdot \mathrm{H}$ abstraction reaction are around $1.2(\mathrm{C} \cdots \cdot \mathrm{H})$ and $1.3 \AA(\mathrm{H} \cdots \mathrm{O})$. This feature indicates that the reactivity predicted by QM/MM-MD simulations for the different $\mathrm{C}-\mathrm{H}$ bonds of the ILE residue can be overestimated since the initially imposed $(\mathrm{C}-) \mathrm{H} \cdot \cdots \cdot \mathrm{OH}$ distance, $1.4 \AA$, could led to a drastic and artificial decrease of the barrier for the $\mathrm{H}$ transfer. In order to reduce this effect, QM/MM-MD simulations on the SARS-CoV-2 protein were repeated but increasing the initial $(\mathrm{C}-) \mathrm{H} \cdots \mathrm{OH}$ distance to $1.7 \AA$. This value is large enough to provide a more realistic description of the reactivity, which is defined by the probability of contact with the right spatial orientation between the $\mathrm{C}-\mathrm{H}$ and $\mathrm{OH}$ groups. QM/MM-MD simulations were performed considering three different cases for each of the ten hydrogen atoms of the ILE residue. Accordingly, a total of $30 \mathrm{QM} / \mathrm{MM}-\mathrm{MD}$ trajectories, $0.5 \mathrm{ps}$ long each one, were run. The results are summarized in Fig. 3c.

A total five trajectories resulted in a successful $\mathrm{H}$ abstraction, which represents $\sim 17 \%$ of the run simulations. No $\cdot \mathrm{H}$ abstraction was achieved for the $\mathrm{C}^{\alpha}-\mathrm{H}, \mathrm{C}^{\beta}-\mathrm{H}$ and $\mathrm{C}^{\delta}-\mathrm{H}$ sites, whereas three and two abstractions occurred at the $\mathrm{C}^{\gamma 1}-\mathrm{H}$ and $\mathrm{C}^{\gamma 2}-\mathrm{H}$ bonds, respectively. This feature suggests that the
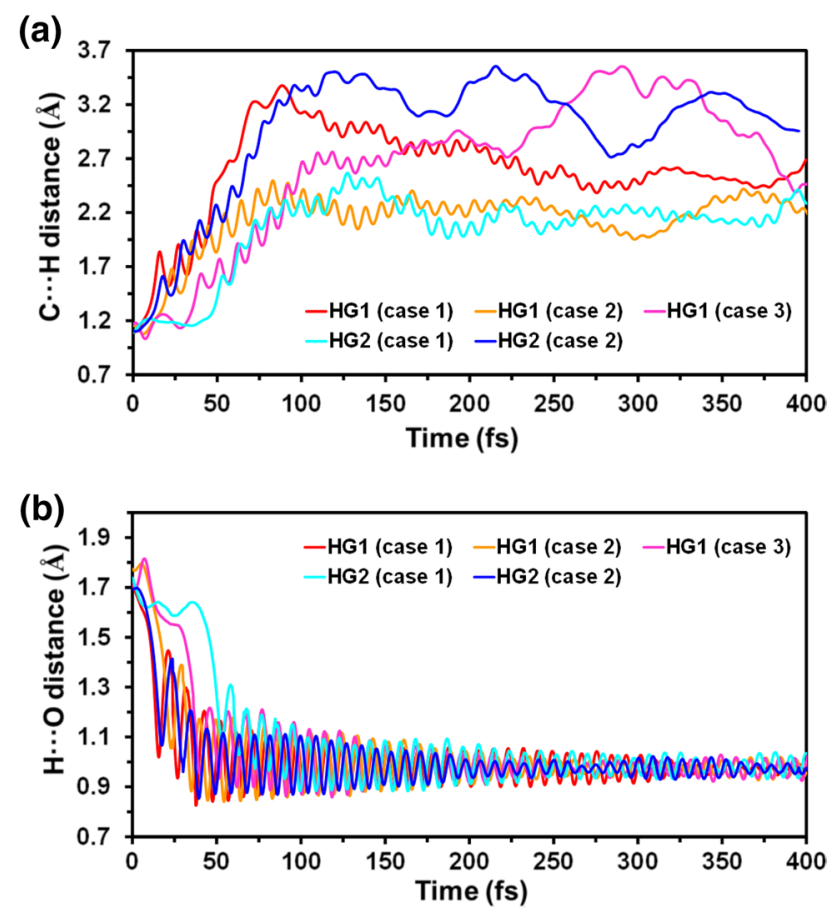

Fig. 4 Temporal evolution of the a $\mathrm{C} \cdots \mathrm{H}$ and $\mathbf{b} \mathrm{H} \cdots \mathrm{O}$ distances involved in the conversion of ILE and OH to ILE and water, respectively, as derived from QM/MM-MD simulations energy barriers for the $\mathrm{H}^{\gamma 1}$ and $\cdot \mathrm{H}^{\gamma 2}$ abstractions are lower than for the other hydrogens, which has been attributed to the higher accessibility of the $\cdot \mathrm{OH}$ radicals to such atoms when ILE forms part of the complex supramolecular structure of the SARS-CoV-2 spike protein. Figure 3c indicates that the $\gamma 2$-radical product ( $\gamma 2$-ILE472) is more stable than the $\gamma 1$-radical one ( $\gamma 1$-ILE472), even though the energy difference found among the products coming from the same reaction site confirms the large influence of the surrounding environment on this $\mathrm{H}$ abstraction process.

Figure $4 \mathrm{a}-\mathrm{b}$ shows the temporal evolution of the $\mathrm{C} \cdots \mathrm{H}$ distance, which is associated with the formation of the radical of ILE472 (.ILE472) through the breaking of the C-H bond, and the $\mathrm{H} \cdots \mathrm{O}$ distance involved in the conversion of .OH to water. As is shown, during the first $50 \mathrm{fs}$ of the trajectories, the $\mathrm{C} \cdots \mathrm{H}$ distance increases from 1.1 to $\sim 1.8 \AA$ while the distance $\mathrm{O} \cdots \mathrm{H}$ decreases from $1.7 \AA$ to $\sim 1.0 \AA$. After this period, the vibration of the $\mathrm{O}-\mathrm{H}$ bond is progressively dampened, while the distance $\mathrm{C} \cdots \mathrm{H}$ of the broken $\mathrm{C}-\mathrm{H}$ bond increases as the water molecule moves away from the reaction site.

Although the capture of the $\cdot \mathrm{H}$ from $\mathrm{C}-\mathrm{H}$ bonds when .OH interacts with the protein was expected, our results allow to conclude that such atom is not extracted from the protein backbone, which would result in the cleavage of the peptide backbone. Instead, a different reaction pathway occurs for the obtained ILE472, in which $\mathrm{H}$ abstraction from exposed amino acid side chains facilitates the protein modification by reaction with ROS in physiological environments. In this work we have analyzed the reaction of -ILE472 from the RBD with both the very reactive $\cdot \mathrm{OH}$ and the nitric oxide radical $(\cdot \mathrm{NO})$, which is produced by NO synthases and is able to modify biomolecules such as proteins, particularly in RNA virus [52]. Two different $200 \mathrm{fs}$ long QM/MM-MD trajectories were run for each -ILE472 ( $\gamma 1$ - and $\gamma 2$-radical products) and each ROS (.OH and $\cdot \mathrm{NO}$ ). For this purpose, the radical was initially approached to a distance of 1.6 and $2.0 \AA$ of the reactive site.

The addition of the two radicals to $\gamma 1$--ILE472 was unsuccessful when the initial distance was of $2.0 \AA$ (Fig. 5ab). Thus, $\mathrm{O} \cdots \mathrm{C}$ and $\mathrm{N} \cdots \mathrm{C}$ distances grew from $2.0 \AA$ to $3.54 \pm 0.05 \AA$ and $3.69 \pm 0.04 \AA$ (averaged over the last $50 \mathrm{fs}$ of trajectory), respectively. Conversely, when the barrier associated with the addition process was artificially reduced by decreasing the initial inter-radical distance to $1.6 \AA$, both the $\gamma 1$-hydroxy-ILE472 and $\gamma 1$-nitro-ILE472 were successfully formed. The resulting average $\mathrm{O}-\mathrm{C}$ and $\mathrm{N}-\mathrm{C}$ bond distances were $1.43 \pm 0.03$ and $1.51 \pm 0.03 \AA$, respectively (Fig. 5c-d). Interestingly, the hydroxylation and nitrosylation of $\gamma 2$--ILE472 was successful in all cases, independently of initial inter-radical distance. Moreover, the obtained O-C and $\mathrm{N}-\mathrm{C}$ distances were practically identical, independently 
(a)

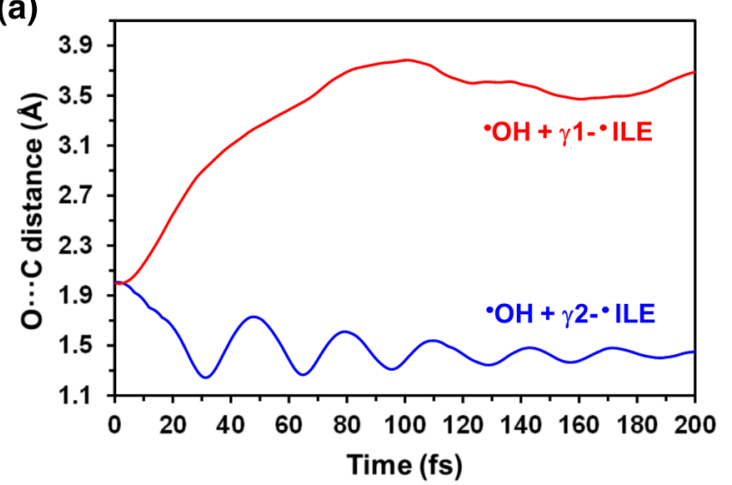

(c)

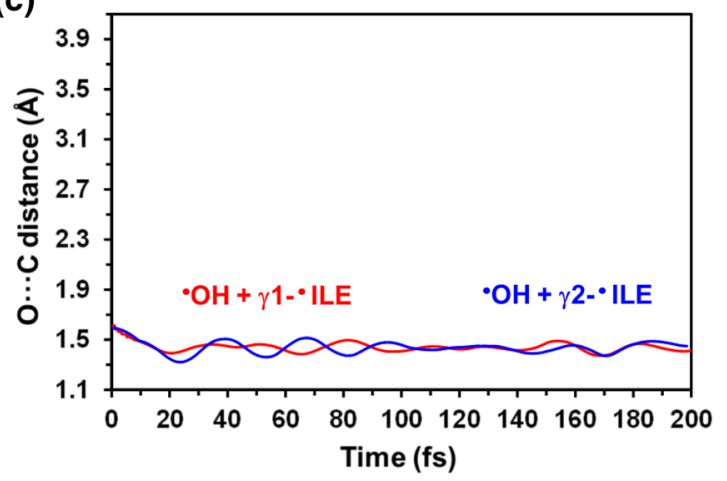

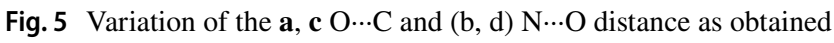
from QM/MM-MD simulations for the following hydroxylation and nitrosylation reactions: a, $\mathbf{c} \mathrm{OH}+\gamma 1$-ILE472 and $\mathrm{OH}+\gamma 2-\mathrm{ILE} 472$;

of the initial inter-radical distance (O-C: $1.42 \pm 0.03 \AA$ and $\mathrm{N}-\mathrm{C}: 1.469 \pm 0.03$ ), as is shown in Fig. 5.

Figure 6 shows the energies of the products obtained from the hydroxylation and nitrosylation of the ILE472 residue and the variation of the $\mathrm{O} \cdots \mathrm{C}$ and $\mathrm{N} \cdots \mathrm{C}$ distances, respectively. As it can be seen, the systems containing $\gamma 1$-hydroxyand $\gamma 1$-nitro-ILE472 are significantly favored with respect to those obtained from the $\gamma 2$-ILE472 reaction. Although this feature is consistent with the fact that $\gamma 2$-ILE472 is more stable than $\gamma 1$-ILE472, the stability of the $\gamma 1$-hydroxyILE product with respect to $\gamma 2$-nitro-ILE has been attributed to the formation of a favorable $\mathrm{N}-\mathrm{H} \cdots \mathrm{O}$ hydrogen bond (Fig. 7a), which is absent in the latter (Fig. 7b).

It is worth noting that the effect of amino acid modifications at the RBD region of the spike protein may affect the protein-protein recognition process [53]. For example, in (b)

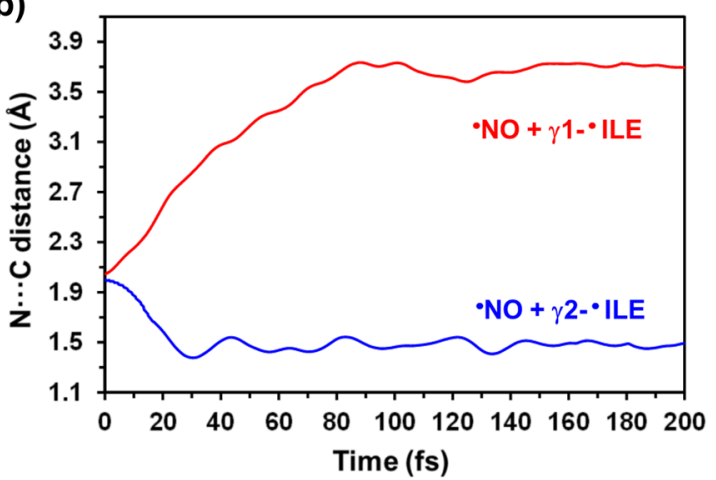

(d)

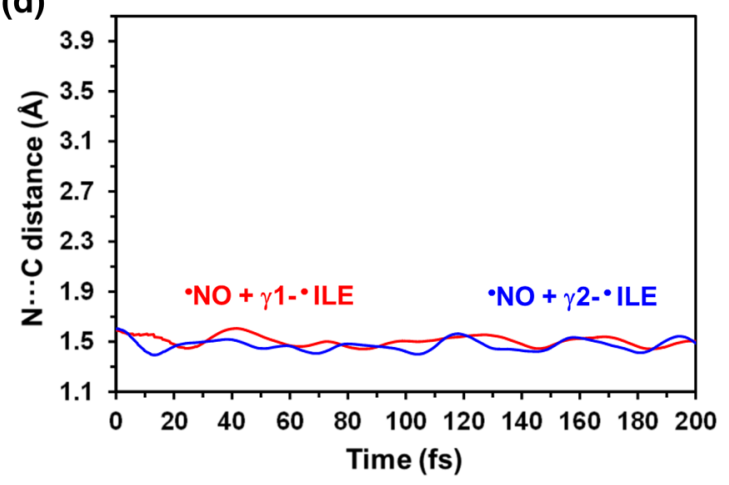

and $\mathbf{b}, \mathbf{d} \mathrm{NO}+\gamma 1$-ILE472 and $\mathrm{NO}+\gamma 2$-ILE472. The initial interradical distance was of $\mathbf{a}, \mathbf{b} 2.0 \AA$ and $\mathbf{c}, \mathbf{d} 1.6 \AA$

addition of the interaction with the backbone of TYR473 (Fig. 7a), the $\gamma 1$-hydroxy-ILE472 residue occasionally interacts with the side group of GLU471 (Fig. 7c) along the MM/QM-MD trajectory. These interactions, which were not detected in the wild type (Fig. 7d), may alter the recognition process of ACE2. Indeed, the incidence of ROS-induced modifications is expected to increase with the relevance of the residue in the recognition mechanism.

Figure 8, which displays the heat-map of RMSD values calculated for all atoms with respect to the crystal for the RBD of $\gamma 1$-hydroxy-ILE472 and $\gamma 2$-nitro-ILE472, indicates that some regions, including the ILE472 residue, undergo major structural alterations. In particular, although many tracts exhibit RMSD values $\leq 3 \AA$, which is reasonably low considering the dynamics of both the backbone and the side chins, the RMSD increases up to values of $9 \AA$ for residues 
Fig. 6 Scheme displaying the results from the reactions of the two ILE472 radicals with the $\mathrm{OH}$ and $\mathrm{NO}^{\prime}$ species as obtained from QM/MM-MD simulations: a $\gamma 1$-ILE472 and b $\gamma 2$-ILE472. The product from each reaction is displayed using a solid sphere model for modified residue. The energy of each product is expressed as the average values for the last $50 \mathrm{fs} \pm$ the standard deviation

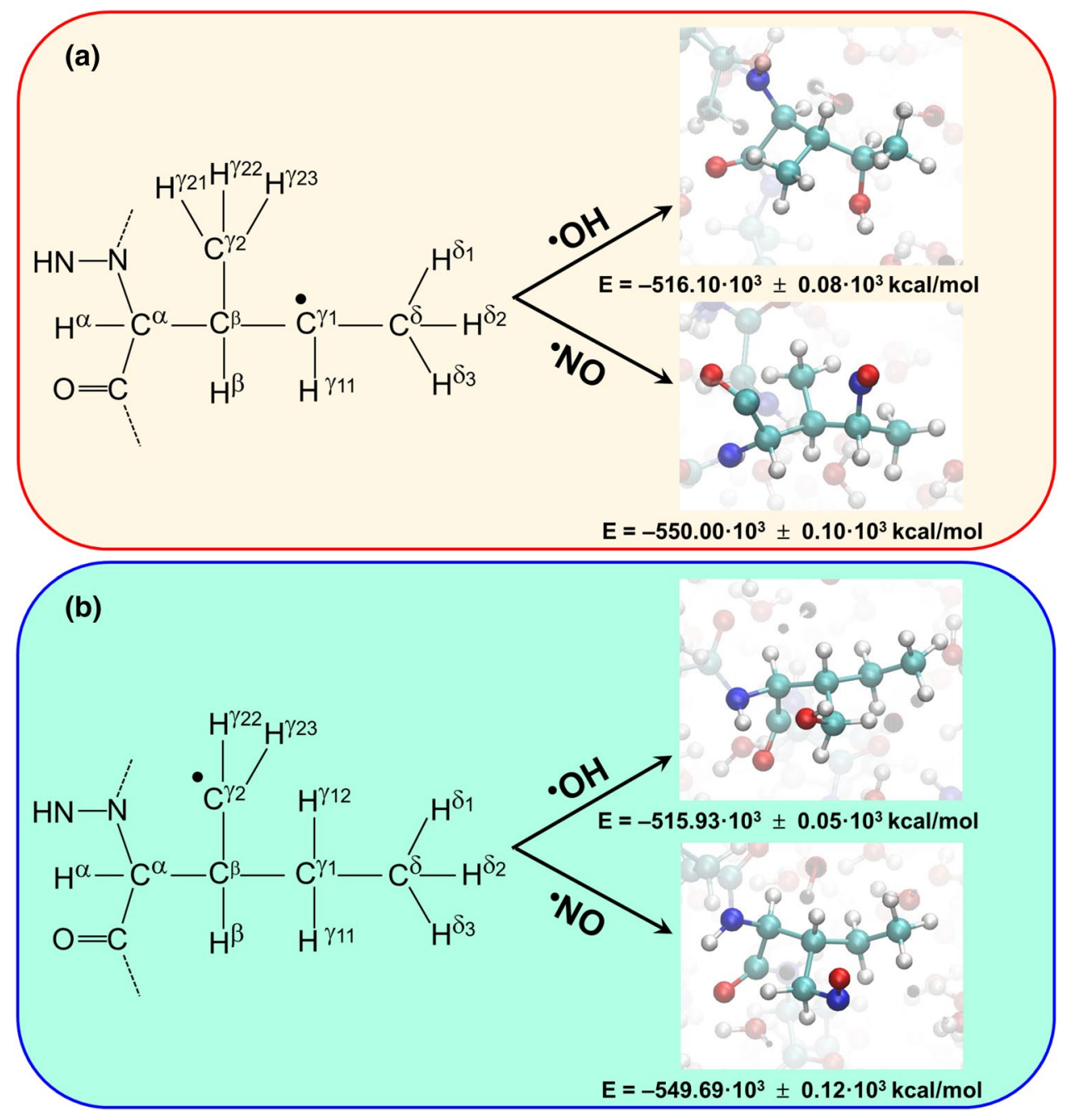

surrounding ILE472. This feature suggests that modifications induced by oxidative stress can play a crucial process in the recognition of $\mathrm{ACE} 2$.

\section{Conclusions}

In summary, the consequences of oxidative stress in the SARS-CoV-2 spike glycoprotein have been modeled in terms of $\mathrm{OH}$-mediated $\mathrm{H}$ abstraction, and the subsequent hydroxylation or nitrosylation of the resulting radical. The results show that ILE residues are accessible and interact with $\mathrm{OH}$. The hydrogen abstraction is more favored at the $\gamma 1$ - and $\gamma 2$-positions of the eight ILE residues located at the RBD. Furthermore, formed $\gamma 1$-ILE and $\gamma 1$-ILE radicals react with $\mathrm{OH}$ and $\mathrm{NO}$ ' species, the hydrogen bonding pattern of the resulting modifications being different from that found for the wild type protein. Multi-scale simulations reveal not only the implications of the oxidative stress in the stability of the RBD but also show that the recognition pattern of the modified residues may change. All in all, in silico results evidence the necessity of experimental studies based on NMR and mass spectrometry to locate and quantify the formation of radicals and modifications in in the SARSCoV-2 spike glycoprotein. 
Fig. 7 a Intramolecular hydrogen interaction between the backbone of TYR473 and the hydroxyl group of $\gamma 1$-hydroxyILE472. b The intramolecular hydrogen interaction between displayed in (a) was not found for $\gamma 2$-nitro-ILE472. b Intramolecular interaction between the carboxylate of GLU471 and the $\gamma 1$-hydroxy-ILE472 residue sporadically formed at the end of the QM/MM-MD trajectory. d Intramolecular hydrogen bonding interactions were not possible in the wild type protein, in which the ILE472 was not mutated
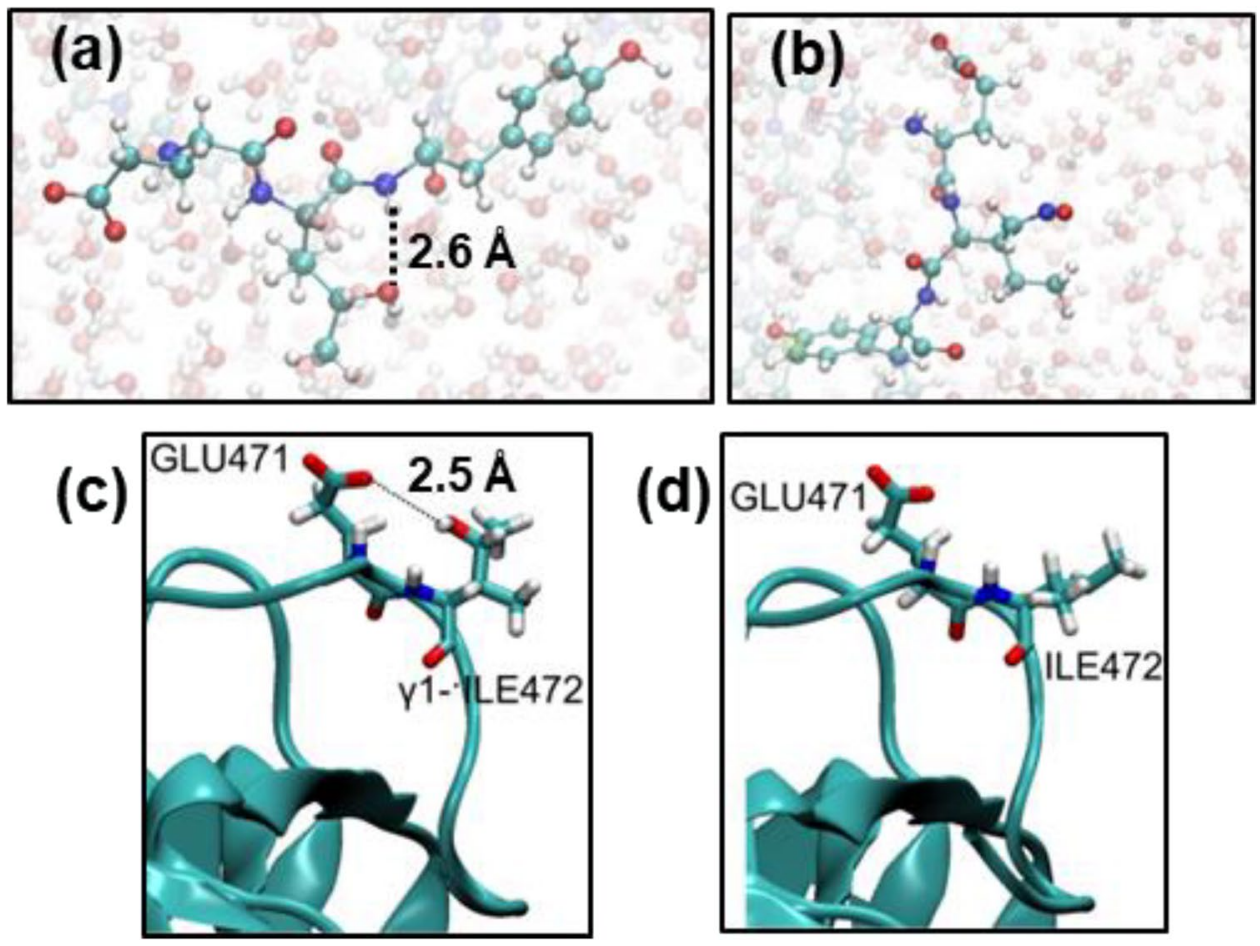


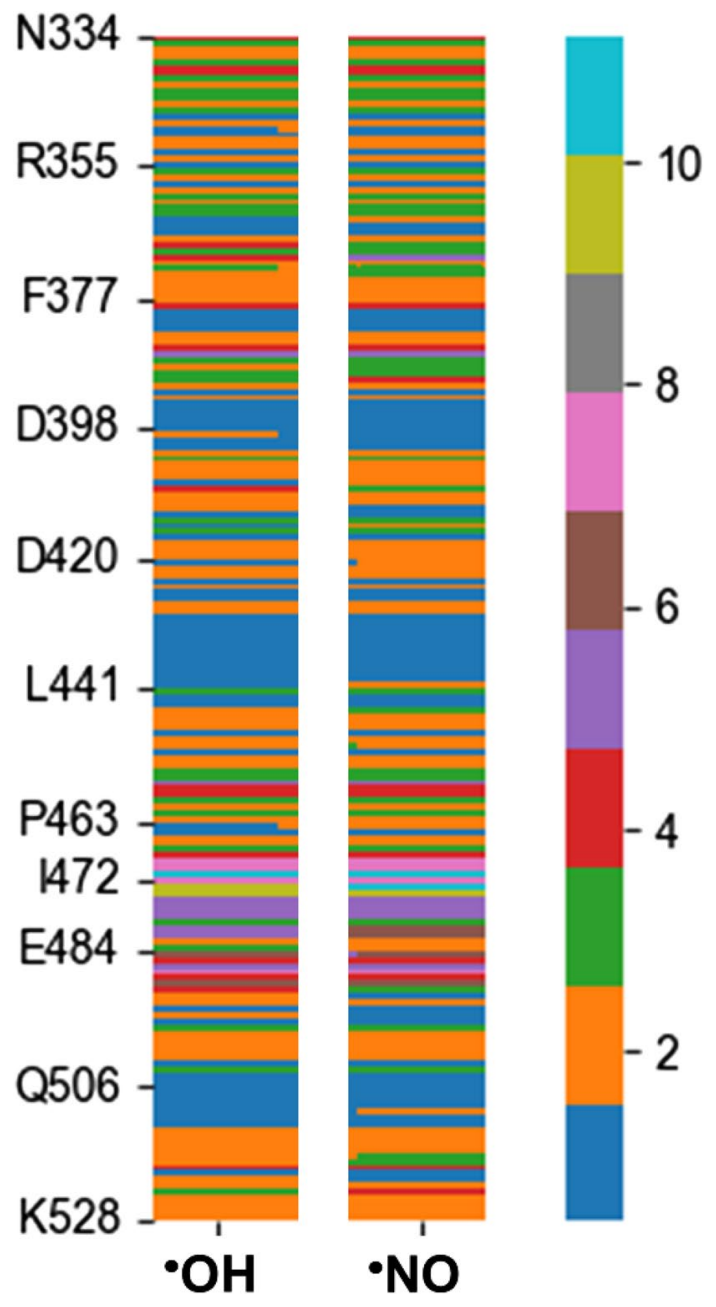

Fig. 8 Heat-map of RMSD values calculated for all atoms with respect to the crystal for the RBD of $\gamma 1$-hydroxy-ILE472 (OH) and $\gamma 2$-nitro-ILE472 (NO)

Acknowledgements J.T. acknowledges "PRACE for awarding us access to Joliot-Curie at GENCI@CEA(Irene), France, through the "PRACE support to mitigate impact of COVID-19 pandemic" call. CA acknowledges AGAUR (2017SGR359) and B. Braun Surgical, S.A.U. for financial support.

Funding Open Access funding provided thanks to the CRUE-CSIC agreement with Springer Nature.

\section{Declarations}

Conflict of interest The authors declare that they have no known competing financial interests or personal relationships that could have appeared to influence the work reported in this paper.

Open Access This article is licensed under a Creative Commons Attribution 4.0 International License, which permits use, sharing, adaptation, distribution and reproduction in any medium or format, as long as you give appropriate credit to the original author(s) and the source, provide a link to the Creative Commons licence, and indicate if changes were made. The images or other third party material in this article are included in the article's Creative Commons licence, unless indicated otherwise in a credit line to the material. If material is not included in the article's Creative Commons licence and your intended use is not permitted by statutory regulation or exceeds the permitted use, you will need to obtain permission directly from the copyright holder. To view a copy of this licence, visit http://creativecommons.org/licenses/by/4.0/.

\section{References}

1. Pizzino G, Irrera N, Cucinotta M, Pallio G, Mannino F, Arcoraci $\mathrm{V}$, Squadrito F, Altavilla D, Bitto A (2017) Oxidative stress: harms and benefits for human health. Oxid Med Cell Longev 2017:8416763. https://doi.org/10.1155/2017/8416763

2. Gonzalez-Dosal R, Horan KA, Rahbek SH, Ichijo H, Chen ZJ, Mieyal JJ, Hartmann R, Paludan SR (2011) HSV infection induces production of ROS, which potentiate signaling from pattern recognition receptors: role for S-glutathionylation of TRAF3 and 6. PLoS Pathog 7:e1002250. https://doi.org/10.1371/journal.ppat. 1002250

3. Ivanov AV, Valuev-Elliston VT, Ivanova ON, Kochetkov SN, Starodubova ES, Bartosch B, Isaguliants MG (2016) Oxidative stress during HIV infection: mechanisms and consequences. Oxid Med Cell Longev 2016:8910396. https://doi.org/10.1155/2016/ 8910396

4. Vlahos R, Stambas J, Selemidis S (2012) Suppressing production of reactive oxygen species (ROS) for influenza a virus therapy. Trends Pharmacol Sci 33:3-8. https://doi.org/10.1016/j. tips.2011.09.001

5. Youn JY, Zhang Y, Wu Y, Cannesson M, Cai H (2021) Therapeutic application of estrogen for COVID-19: Attenuation of SARS-CoV-2 spike protein and IL-6 stimulated, ACE2-dependent NOX2 activation, ROS production and MCP-1 upregulation in endothelial cells. Redox Biol 46:102099. https://doi.org/10. 1016/j.redox.2021.102099

6. Barhoumi T, Alghanem B, Shaibah H, Mansour FA, Alamri H, Akiel MA, Alroqi F, Boudjelal Mohammad M (2021) SARSCoV-2 coronavirus spike protein-induced apoptosis, inflammatory, and oxidative stress responses in thp-1-like-macrophages: potential role of angiotensin-converting enzyme inhibitor (perindopril). Front Immunol 12:3771. https://doi.org/10.3389/ fimmu.2021.728896

7. Iftimie S, López-Azcona AF, Vicente-Miralles M, DescarregaReina R, Hernández-Aguilera A, Riu F, Simó JM, Garrido P, Joven J, Camps J, Castro A (2020) Risk factors associated with mortality in hospitalized patients with SARS-CoV-2 infection a prospective, longitudinal, unicenter study in Reus, Spain. PLoS One 15:e0234452. https://doi.org/10.1371/journal.pone.02344 52

8. Nishiga M, Wang DW, Han Y, Lewis DB, Wu JC (2020) COVID19 and cardiovascular disease: from basic mechanisms to clinical perspectives. Nat Rev Cardiol 17:543-558. https://doi.org/10. 1038/s41569-020-0413-9

9. Schwarz KB (1996) Oxidative stress during viral infection: a review. Free Radic Biol Med 21:641-649. https://doi.org/10.1016/ 0891-5849(96)00131-1

10. Liu M, Chen F, Liu T, Chen F, Liu S, Yang J (2017) The role of oxidative stress in influenza virus infection. Microb Infect 19:580586. https://doi.org/10.1016/j.micinf.2017.08.008

11. Khomich OA, Kochetkov SN, Bartosch B, Ivanov AV (2018) Redox biology of respiratory viral infections. Viruses 10:392. https://doi.org/10.3390/v10080392

12. Ciriolo MR, Palamara AT, Incerpi S, Lafavia E, Bue MC, De Vito P, Garaci E, Rotilio G (1997) Loss of GSH, oxidative stress, and 
decrease of intracellular $\mathrm{pH}$ as sequential steps in viral infection. J Biol Chem 272:2700-2708. https://doi.org/10.1074/jbc.272.5. 2700

13. Ibrahim IH, Ellakwa DES (2021) SUMO pathway, blood coagulation and oxidative stress in SARS CoV-2 infection. Biochem Biophys Rep 26:100938. https://doi.org/10.1016/j.bbrep.2021. 100938

14. Kzolov EM, Vanova E, Grechno AV, Wu WK, Starodubova AV, Orekhov AN (2021) Involvement of oxidative stress and the innate immune system in SARS-CoV-2 infection. Diseases 9:17. https://doi.org/10.3390/diseases9010017

15. Chang R, Manum A, Dominic A, Le NT (2021) SARS-CoV-2 Mediated endothelial dysfunction: the potential role of chronic oxidative stress. Front Physiol 11:605908. https://doi.org/10. 3389/fphys.2020.605908

16. Suhail S, Zajac J, Fossum C, Lowater H, McCracken C, Severson N, Laatsch B, Narkoewicz-Jodko A, Johnson B, Liebau J, Bhattacharyya S, Hati S (2020) Role of oxidative stress on SARS-CoV (SARS) and SARS-CoV-2 (COVID-19) infection: a review. Prot J 39:644-656. https://doi.org/10.1007/ s10930-020-09935-8

17. Sies H (1993) Strategies of antioxidant defense. Eur J Biochem 215:213-219. https://doi.org/10.1111/j.1432-1033.1993.tb180 25.x

18. Kuwano K, Nakashima N, Inoshima I, Hagimoto N, Fujita M, Yoshimi M, Maeyama T, Hamada N, Watanabe K, Hara N (2003) Oxidative stress in lung epithelial cells from patients with idiopathic interstitial pneumonias. Eur Respir J 21:232-240. https:// doi.org/10.1183/09031936.03.00063203

19. Valyi-Nagy T, Dermody TS (2005) Role of oxidative damage in the pathogenesis of viral infections of the nervous system. Histol Histopathol 20:957-967. https://doi.org/10.14670/HH-20.957

20. Prieto-Bermejo R, Romo-González M, Pérez-Fernández A, Ijurko C, Hernández-Hernández A (2018) Reactive oxygen species in haematopoiesis: leukaemic cells take a walk on the wild side. J Exp Clin Cancer Res 37:125. https://doi.org/10.1186/ s13046-018-0797-0

21. Kennett EC, Chuang CY, Degendorfer G, Whitelock JM, Davies MJ (2011) Mechanisms and consequences of oxidative damage to extracellular matrix. Biochem Soc Trans 39:1279-1287. https:// doi.org/10.1042/BST0391279

22. Walls AC, Park YJ, Tortorici MA, Wall A, McGuire AT, Veesler D (2020) Structure, function, and antigenicity of the SARS-CoV-2 spike glycoprotein. Cell 180:281-292. https://doi.org/10.1016/j. cell.2020.02.058

23. Webb B, Sali A (2016) Comparative protein structure modeling using modeller. Curr Protoc Protein Sci 54:561-537. https://doi. org/10.1002/cpbi.3

24. Pettersen EF, Goddard TD, Huang CC, Couch GS, Greenblatt DM, Meng EC, Ferrin TE (2004) UCSF Chimera-a visualization system for exploratory research and analysis. J Comput Chem 25:1605-1612. https://doi.org/10.1002/jcc.20084

25. Case DA, Cheatham TE III, Darden T, Gohike H, Luo R, Merz KM Jr, Onufriey A, Simmerling C, Wang B, Woods RJ (2005) The Amber biomolecular simulation programs. J Comput Chem 26:1668-1688. https://doi.org/10.1002/jcc.20290

26. Case DA, Ben-Shalom IY, Brozell SR, Cerutti DS, Cheatham TE III, Cruzeiro VWD, Darden TA, Duke RE, Ghoreishi D, Gilson MK, Gohlke H, Goetz AW, Greene D, Harris R, Homeyer N, Huang Y, Izadi S, Kovalenko A, Kurtzman T, Lee TS, LeGrand S, Li P, Lin C, Liu J, Luchko T, Luo R, Mermelstein DJ, Merz KM, Miao Y, Monard G, Nguyen C, Nguyen H, Omelyan I, Onufriev A, Pan F, Qi R, Roe DR, Roitberg A, Sagui C, Schott-Verdugo S, Shen J, Simmerling CL, Smith J, Salomon-Ferrer R, Swails
J, Walker RC, Wang J, Wei H, Wolf RM, Wu X, Xiao L, York DM, Kollman PA (2018) Amber. University of California, San Francisco

27. Maier JA, Martinez C, Kasavajhala K, Wickstrom L, Hauser KE, Simmerling C (2015) ff14SB: Improving the accuracy of protein side chain and backbone parameters from ff99SB. J Chem Theory Comput 11:3696-3713. https://doi.org/10.1021/acs.jctc.5b00255

28. Kirschner KN, Yongye AB, Tschampel SM, González-Outeiriño J, Daniels CR, Foley BL, Woods RJ (2008) GLYCAM06: a generalizable biomolecular force field. Carbohydrates J Comput Chem 29:622-655. https://doi.org/10.1002/jcc.20820

29. Jorgensen WL, Chandrasekhar J, Madura JD, Impey RW, Klein ML (1983) Comparison of simple potential functions for simulating liquid water. J Chem Phys 79:926-935. https://doi.org/10. 1063/1.445869

30. Martí D, Torras J, Bertran O, Turon P, Alemán C (2021) Temperature effect on the SARS-CoV-2: a molecular dynamics of the spike homotrimeric glycoprotein. Comput Struct Biotechnol 19:1848-1862. https://doi.org/10.1016/j.csbj.2021.03.037

31. Roeselová M, Jungwirth P, Tobias DJ, Gerber RB (2003) Impact, trapping, and accommodation of hydroxyl radical and ozone at aqueous salt aerosol surfaces. a molecular dynamics study. J Phys Chem B 107:12690-12699. https://doi.org/10.1021/jp030592i

32. Huber KP, Herzberg G (1979) Molecular spectra and molecular structure. constants of diatomic molecules. Springer, Boston

33. Izaguirre JA, Catarello DP, Wozniak JM, Skeel RD (2001) Langevin stabilization of molecular dynamics. J Chem Phys 114:2090-2098. https://doi.org/10.1063/1.1332996

34. Toukmaji A, Sagui C, Board J, Darden T (2000) Efficient particlemesh Ewald based approach to fixed and induced dipolar interactions. J Chem Phys 113:10913-10927. https://doi.org/10.1063/1. 1324708

35. Torras J, Deumens E, Trickey SB (2006) Software integration in multi-scale simulations: the PUPIL system. J Comput-Aided Mater 13:201-212. https://doi.org/10.1007/s10820-006-9011-3

36. Torras J, Seabra GdM, Deumens E, Trickey SB, Roitberg AE (2008) A versatile Amber-Gaussian QM/MM interface through PUPIL. J Comput Chem 29:1564-1573. https://doi.org/10.1002/ jcc. 20915

37. Bylaska EJ, Jong WAd, Govind N, Kowalski K, Straatsma TP, Valiev M, Wang D, Apra E, Windus TL, Hammond J, Nichols P, Hirata S, Hackler MT, Zhao Y, Fan PD, Harrison RJ, Dupuis M, Smith DMA, Nieplocha J, Tipparaju V, Krishnan M, Wu Q, Van Voorhis T, Auer AA, Nooijen M, Brown E, Cisneros G, Fann GI, Fruchtl H, Garza J, Hirao K, Kendall R, Nichols JA, Tsemekhman K, Wolinski K, Anchell J, Bernholdt D, Borowski P, Clark T, Clerc D, Dachsel H, Deegan M, Dyall K, Elwood D, Glendening E, Gutowski M, Hess A, Jaffe J, Johnson B, Ju J, Kobayashi R, Kutteh R, Lin Z, Littlefield R, Long X, Meng B, Nakajima T, Niu S, Pollack L, Rosing M, Sandrone G, Stave M, Taylor H, Thomas G, Van Lenthe J, Wong A, Zhang Z, Chem NW (2007) A computational chemistry package for parallel computers 5.1. Pacific Northwest National Laboratory, Richland

38. Zhao Y, Truhlar DG (2008) The M06 suite of density functionals for main group thermochemistry, thermochemical kinetics, noncovalent interactions, excited states, and transition elements: two new functionals and systematic testing of four M06-class functionals and 12 other functionals. Theor Chem Acc 120:215241. https://doi.org/10.1007/s00214-007-0310-x

39. Zhao Y, Truhlar DG (2008) Density functionals with broad applicability in chemistry. Acc Chem Res 41:157-167. https:// doi.org/10.1021/ar700111a

40. Nukuna BN, Goshe MB, Anderson VE (2001) Sites of hydroxyl radical reaction with amino acids identified by ${ }^{2} \mathrm{H}$ 
NMR detection of induced ${ }^{1} \mathrm{H} /{ }^{2} \mathrm{H}$ exchange. J Am Chem Soc 12:1208-1214. https://doi.org/10.1021/ja003342d

41. Cheiber S, Kar T (2010) Analysis of the ractivities of protein $\mathrm{C}-\mathrm{H}$ bonds to $\mathrm{H}$ atom abstraction by $\mathrm{OH}$ radical. J Am Chem Soc 132:16450-16459. https://doi.org/10.1021/ja105204v

42. Kurosaki Y, Ueda MT, Nakano Y, Yasuda J, Koyanagi Y, Sato K, Nakagawa S (2018) Different effects of two mutations on the infectivity of Ebola virus glycoprotein in nine mammalian species. J Gen Virol 99:181-188. https://doi.org/10.1099/jgv.0. 000999

43. Babcock GJ, Esshaki DJ, Thomas WD Jr, Ambrosino DM (2004) Amino acids 270 to 510 of the severe acute respiratory syndrome coronavirus spike protein are required for interaction with receptor. J Virol 78:4552-4560. https://doi.org/10.1128/jvi.78.9.45524560.2004

44. Torras J, Aleman C (2018) Massive quantum regions for simulations on bio-nanomaterials: synthetic ferritin nanocages. Chem Comm 54:2118-2121. https://doi.org/10.1039/C7CC09512K

45. Chen J, Wang R, Wang M, We GW (2020) Mutations strengthened SARS-CoV-2 infectivity. J Mol Biol 432:5212-5226. https://doi. org/10.1016/j.jmb.2020.07.009

46. Volz E, Hill V, McCrone JT, Price A, Jorgensen D, O'Toole Á, Southgate J, Johnson R, Jackson B, Nascimento FF, Rey SM, Nicholls SM, Colquhoun RM, da Silva FA, Shepherd J, Pascall DJ, Shah R, Jesudason N, Li K, Jarrett R, Pacchiarini N, Bull M, Geidelberg L, Siveroni I, Goodfellow I, Loman NJ, Pybus OG, Robertson DL, Thomson EC, Rambaut A, Connor TR (2020) Evaluating the effects of SARS-CoV-2 spike mutation D614G on transmissibility and pathogenicity. Cell 184:64-75. https://doi.org/ 10.1016/j.cell.2020.11.020
47. Xu G, Chance MR (2007) Hydroxyl radical-mediated modification of proteins as probes for structural proteomics. Chem Rev 107:3514-3543. https://doi.org/10.1021/cr0682047

48. Stadtman ER (1993) Oxidation of free amino acids and amino acid residues in proteins by radiolysis and by metal-catalyzed reactions. Annu Rev Biochem 62:797-821. https://doi.org/10.1146/ annurev.bi.62.070193.004053

49. Burgess VA, Easton CJ, Hay MP (1989) Selective reaction of glycine residues in hydrogen atom transfer from amino acid derivatives. J Am Chem Soc 111:1047-1052. https://doi.org/10.1021/ ja00185a039

50. Amos RIJ, Chan B, Easton CJ, Random L (2015) Hydrogen-atom abstraction from a model amino acid: dependence on the attacking radical. J Phys Chem B 119:783-788. https://doi.org/10.1021/ jp505217q

51. Liu XR, Zhang MM, Zhang B, Rempel DL, Gross ML (2019) Hydroxyl-radical reaction pathways for the fast photochemical oxidation of proteins platform as revealed by ${ }^{18} \mathrm{O}$ isotopic labelling. Anal Chem 91:9238-9245. https://doi.org/10.1021/acs.analc hem.9b02134

52. Akaike $\mathrm{T}$ (2001) Role of free radicals in viral pathogenesis and mutation. Rev Med Virol 11:87-101. https://doi.org/10.1002/rmv. 303

53. Peng Y, Alexov E, Basu S (2019) Structural perspective on revealing and altering molecular functions of genetic variants linked with diseases. Int J Mol Sci 20:548. https://doi.org/10.3390/ijms2 0030548

Publisher's Note Springer Nature remains neutral with regard to jurisdictional claims in published maps and institutional affiliations.

\title{
Authors and Affiliations
}

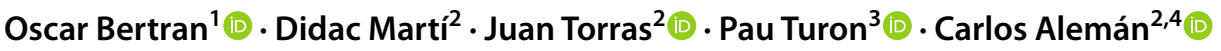 \\ Oscar Bertran \\ oscar.bertran@upc.edu \\ $\triangle$ Juan Torras \\ joan.torras@upc.edu \\ $\triangle$ Pau Turon \\ pau.turon@bbraun.com \\ $\triangle$ Carlos Alemán \\ carlos.aleman@upc.edu \\ 2 Departament d'Enginyeria Química (DEQ) and Barcelona \\ Research Center in Multiscale Science and Engineering, \\ EEBE, Universitat Politècnica de Catalunya (UPC), \\ C/Eduard Maristany 10-14, 08019 Barcelona, Spain \\ 3 B. Braun Surgical, S.A.U. Carretera de Terrasa 121, \\ 08191 Rubí, Barcelona, Spain \\ 4 Institute for Bioengineering of Catalonia (IBEC), The \\ Barcelona Institute of Science and Technology, Baldiri \\ Reixac 10-12, 08028 Barcelona, Spain
}

1 Departament de Física EETAC, Universitat Politècnica de Catalunya, c/Esteve Terrades, 7, 08860 Castelldefels, Spain 